\title{
Redesign of Clinical Practicum for End of Life Care with Integrated Perspectives
}

\author{
Sanghee Kim \\ Yonsei University College of Nursing \& Mo Im Kim Nursing Research Institute, Seoul, Korea \\ Email: sangheekim@yuhs.ac
}

How to cite this paper: Kim, S. (2017) Redesign of Clinical Practicum for End of Life Care with Integrated Perspectives. Open Journal of Nursing, 7, 1172-1180. https://doi.org/10.4236/ojn.2017.710085

Received: March 20, 2017

Accepted: October 24, 2017

Published: October 27, 2017

Copyright $\odot 2017$ by author and Scientific Research Publishing Inc. This work is licensed under the Creative Commons Attribution International License (CC BY 4.0).

http://creativecommons.org/licenses/by/4.0/

\section{c) (i) Open Access}

\begin{abstract}
With the cycling of nursing research, theory, practice, education, and policy making, nursing knowledge has been developed and disseminated. A clinical practicum is a good way to deliver nursing knowledge. Also an area of end-of-life (EOL) care is a good field to integrate nursing knowledge with different perspectives and multiple ways of knowing. The purposes of this paper were 1) to describe nursing knowledge and EOL with an integrated view, 2) to critique the current phenomenon of the field of EOL, and 3) to propose a redesign of the clinical practicum in EOL care. An integrative review was performed as the method of the study. The results showed that the reflection of nursing knowledge from different perspectives regarding EOL may help the nursing discipline develop various nursing knowledge, practice, education, and research. However, this paper shows that recent education is more focused on empirical knowledge, problem-solving approaches with a totality paradigm, and didactic teaching-learning methods. For redesigning the clinical practicum, it is necessary to reestablish a caring relationship between nursing instructors and nursing students. In terms of the teaching-learning process, the human-becoming teaching-learning process is recommended over the nurse-becoming process.
\end{abstract}

\section{Keywords}

Nursing Education, Palliative Care, Nursing Faculty Practice

\section{Introduction}

In nursing discipline, philosophy of nursing, metaparadigm, theory as well as research, practice, and education contribute to build and disseminate nursing knowledge with interaction of each other. Nursing scholars, educated nursing theory and research within their specialty in practice, have responsibilities on 
connecting dots among knowledge, research, education and practice to developing and disseminating their knowledge through education, research, and advanced practice as clinical leaders [1].

End of life (EOL) care is a good field to integrate nursing knowledge from different perspectives and multiple ways of knowing. And clinical practicum is a good way to integrate nursing knowledge, education, research, and practice as well as a good exercise to deliver integrated nursing knowledge to next generation.

The purposes of this paper are: 1) to reflect on nursing knowledge and EOL; 2) to discuss integrated view of EOL; 3) to critique of current phenomenon of EOL area; 4 ) to propose redesign clinical practicum in EOL area. This sequential activity gives a sense to clinical leader of doctorally prepared nurses to integrate knowledge, research, and education in their specialty area.

\section{Reflection of Nursing Knowledge and End of Life}

In nursing discipline, philosophy from different perspectives exists together. Based on Parse [2], two prominent paradigms in nursing were defined as totality and simultaneous paradigm. Newman, Sime, \& Corcoran-Perry [3] described three different perspectives as particulate-deterministic perspectives, interactive-integrative perspectives, and unitary-transformative perspectives. Recently, Roy \& Jones [4] described three different philosophical underpinning, namely, paradigm as knowledge as a problem-solving, knowledge as a process, and knowledge as integrative. These different philosophical underpinnings and paradigms give nursing discipline different methods of inquiry and practice.

In nursing practice, knowledge regarding empiric, esthetic, ethic, personal, and sociopolitical area can help nursing reach at best practice for patient care [5] [6] [7]. Chinn \& Kramer suggested that the way of the best practice is integrating nursing knowledge as well as critical reflection and action to change [7]. According to Chinn \& Kramer, the best practices depend on integrating empirical, ethics, aesthetics and personal knowledge to form a whole. Also, praxis, interaction between critical reflection beyond critical thinking and thoughtful reflection and action, creates future.

In EOL care, these different paradigms and multiple ways of knowing may help nursing discipline be profound, concrete and specific approach in practice. Therefore, reflection of nursing knowledge from different perspectives regarding EOL may help nursing discipline develop various nursing knowledge, practice, education, and research. But for the best practice in EOL, it is necessary for integration and praxis through critical reflection and action to change as a whole form in terms of nature of person and focus of nursing.

\subsection{Nature of Person}

Nature of person is an object of nursing forever. From the problem solving perspectives, human can be understood by bio-psychosocial being, interacting 
within an environment. From the perspective of knowledge as process, human experience is understood as a dynamic partnership through dialogue [8]. From the perspective of integrative knowledge as cosmic imperatives, human is understood with unity, purposefulness, and promise [9].

In EOL care situation, how nursing does apply understanding nature of person? In totality paradigm, EOL patient is understood as a whole consists of mind, body, and spirit. In simultaneous paradigm, nature of person is understood as unitary human being and holistic person which is not a summation of part but more than one. In nursing discipline specific perspectives, nature of person is understood by human-being, an intentional and free beings actively participate in their life and choose ways of being-becoming [10]. With Newman's perspectives [11], person can be identified unitary, undivided, and unfolding nature of pattern in death and dying process. With Roy's cosmic imperatives [9], human is a unique creature with specific purpose.

\subsection{Focus of Nursing}

What is focus of nursing? Focus of Nursing can be understood by either doing something or being with some/others. According to Jones [8], focus of nursing is understood either identification problems within problem-solving approach or nurses' engagement with person within nursing as a process perspectives.

In EOL, in terms of doing, within problem solving approach, empiric knowledge is more highlighted such as symptom management and pain management. In terms of doing good, ethical knowledge is required. With the focus of nursing as being, personal knowing and esthetic knowing are more focused including communication skill and understanding their experience. With focus of nursing as moving forward to Health as Expanding Consciousness (HEC) or humanbecoming, finding meaning of EOL is essential.

\section{Integrated View of End of Life Care}

Decision about what nurse ought to do in EOL is a sequential process of choosing good for patient. Through integration based on both deeper understanding with knowledge from process perspectives and critical thinking used with knowledge from problem-solving perspectives, the action to change accomplished. Also, it is necessary to integration of empiric, esthetic, personal, ethical, socio-political knowledge in EOL area. Understanding about empiric knowledge such as proper symptom management, esthetic knowledge such as finding meaning and significance in EOL, ethical knowledge such as nurses' responsibility and justification for decision making, personal knowledge such as therapeutic use of self, and socio-political knowledge such as legal boundary of EOL and cultural differences may help nurses improve EOL care for patient.

For example, for ethical decision making regarding EOL care, integration of nursing knowledge from different perspectives may expand nurses' role and be rich at patient care area. 
The Advance Directive Decision-Making (ADDM) model, developed by Goodwin, Kiehl, and Peterson [12] based on King's conceptual systems and theory of goal attainment, gives a sense that systems, personal, interpersonal, and social systems relate to decision making for end of life decisions for both patients and nurses. The theory of peaceful end of life, constructed by Ruland and Moore [13], provides a theoretical framework in terms of nurses' action taken for an outcome of end-of-life care: not being in pain, the experience of comfort, the experience of dignity and respect, being at peace, and closeness to significant others or other caring persons. The theory of optimizing stewardship developed by Breakey [14] explained the integration process nurses used to provide the necessary supports to patients and families during both the illness experience and decision making process. Overall, Newman's theory of health as expanding consciousness [11] provides a view of a nurse's responsibility as a partner. Through the outcome of an ethical decision, both nurse and patient can reach transcendence, such as satisfaction, and find meaning in life and death [15] [16].

\section{Critique of Current Phenomenon in EOL within Integrated Perspectives}

In contrast that nursing discipline has tried to integrate knowledge from different perspectives and multiple ways of knowing, the area of nursing practice, research, and education seems to be still biased and more focused on one of predominant perspectives.

In EOL area, what does happen to patient facing on EOL in nursing practice? Research outcome revealed patients have struggled with poor symptom management, experienced fear to death. Both health care professionals and patients experienced poor communication between patient and health care provider, confusion their role within interdisciplinary team [17]. Research outcome for nurses often reported they struggled with moral distress, powerlessness and so on [18]. To overcome these problems, increasing health care providers' awareness and knowledge regarding EOL suggested. End of Life Nursing Education Consortium (ELNEC) project movement and End of Life Physician Education Consortium (EPEC) have been proposed [19] [20] [21]. Is it enough? I don't agree it is enough. Education is focused on empiric knowledge, problem solving approach with totality paradigm, and didactic teaching-learning methods.

\section{Redesign a Practice Environment: Integration among End of Life Care within Clinical Practicum in Korea}

\subsection{Significance}

Nursing is practical science and human science as well. Knowledge through research, practice, and education not only affect to develop and/or evolve new knowledge, but also affect to disseminate through each other like a pyramid and a reverse pyramid. To reach at optimal patients' outcome and save health care cost, nurse dose including dose (number of nurses or amount of care by nurses), nurse 
(education, expertise, and experience), and host and host response (organizational or patient receptiveness) are equally important [22].

Clinical practicum is a field to meet education, practice, and knowledge with research utilization for the next generation of nursing. So, clinical practicum ought to be planned with insight about what we know and what we ought to do. Clinical practicum is a good way to exercise integration knowledge about different perspectives and multiple ways of knowing with discipline specific view. In Korea, clinical practicum is performed by various nursing instructor at levels from nursing faculty members to part time instructor [23]. It is implemented by focusing on nursing process. Therefore, to deliver integrated nursing knowledge and to integrate education, practice, research, and knowledge for the next generation, redesign of clinical practicum regarding EOL is proposed as Figure 1 illustrated.

\subsection{Objectives for Redesigning Clinical Practicum}

In EOL situation, to reach at peaceful end of life for terminally ill patients, well-trained and educated nurses are essential. According to Bunkers [24], nursing education need to move from a medical model to a nursing model of unitary lived experiences. And suggested four challenges: explicating the unitary nature of humankind, living the responsibility of expressing new thought, perceiving teaching-learning as engaging community, and visioning nursing leadership as a transformative presence in change.

Goal to change is transform integrative knowledge to practice via clinical practicum in EOL care setting to improve patient care. Specific objectives are: to integrate clinical reasoning, to understand patient and family faced on EOL, to have unitary perspectives in nursing.

\subsection{Setting \& Samples}

As a specific setting, EOL care practice is a good way to integrate nursing knowledge and demonstrate different paradigms and multiple ways of knowing. As

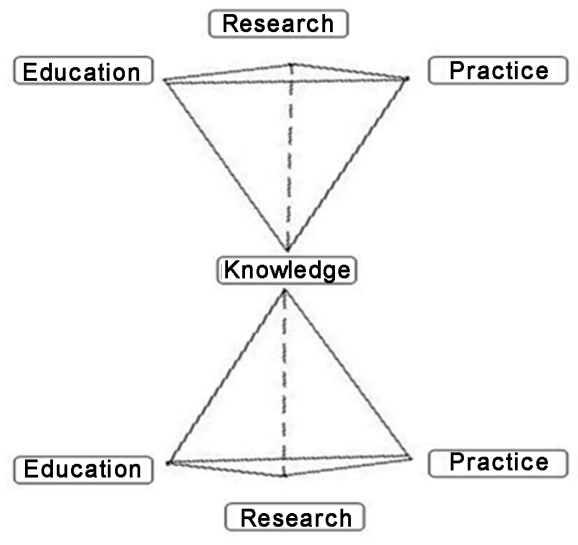

Figure 1. Development and dissemination of nursing knowledge. 
specific samples, nursing senior student will be recruited as a population of applying this redesigned clinical practicum.

\subsection{Methods}

As a method, redesigned clinical practicum of end of life can be applied by establishing caring relationship, human-becoming teaching-learning process and reflection. First, it needs to reestablish relationship in between both nursing instructor and nursing student. Caring relationship, major part in nursing discipline, can be exercised in clinical practicum. Caring relationship between nursing student and instructor based on partnership and establishing mutual understanding is a way to enhancing integration nursing knowledge. Exercising caring relationship is a way to linking caring science and HEC as well. Jones [8] asserted that HEC support nurse-patient relationship experienced through a caring partnership. Mutual understanding and goal attainment based on partnership among each other.

Second, it needs to reestablish teaching-learning process. According to Parse's human becoming, health is the living of day-to-day ways of being in the world. Nurses have the responsibility to guide humans toward ways of being, finding meaning in situation, and choosing ways to co-create their health with true presence between the nurse and patients' life. Human becoming teaching-learning process can be matched to nurse-becoming process. Human-becoming teachinglearning process is seen as a template for students' connections to people experiencing nursing care and to other clinician [25]. In clinical practicum, doctorally prepared nurses can apply strategy "training for trainers" in their practice area. So, caring relationship can be established with triad relationship in dual matrix. The first triad consists of PhD nurse (or nursing faculty), nursing preceptor (trainer), and patient. And the second triad consists of nursing preceptor, nursing student, and patient. Demonstrating doctorally prepared nurses' role is a way to becoming novice nurse to expert nurse within the triad of $\mathrm{PhD}$ nurse, nursing preceptor, and patient. By delivering same idea, nursing student can be learned by nursing preceptor to become a nurse.

Third, critical reflection is a particular way to integrating different paradigm and emerging multiple ways of knowing [26]. Both using nursing process and narrative pedagogy can help nursing student have balance between problem-solving paradigm and knowledge as a process paradigm. Recently, narrative pedagogy, using case study or story telling, has been concerned about clinical practicum in the literature [25] [27].

There is an example of applying these Forneris \& Peden-McAlpine [28] suggested 'contextual learning methods' as a reflective learning intervention including narrative reflective journaling, individual interviews, preceptor coaching, and leader-facilitated discussion groups.

Even though new trial to synthesize and integrate is need, still it remains about issues regarding redesigned clinical practicum are how to evaluate this 
practicum and how to apply to research area. The question about "Is it effectiveness or what extent this redesign clinical practicum improve practice in end of life?" should be answered as well.

\section{Conclusion}

This paper discussed nursing knowledge from different perspectives in the specialty of EOL area. As nursing is a practical and human science, nurses need integrative knowledge. In this paper, to deliver integrative knowledge to practice, redesign clinical practicum is proposed for next generation. In the EOL area, by re-establishing caring relationship between nursing instructor and nursing student, with human becoming teaching-learning process and reflection, nursing students are expected to exercise and expose integrated nursing knowledge and practice.

\section{Acknowledgements}

Author thanks Drs. Dorothy A. Jones, Pamela J. Grace at Boston College and Won Hee Lee at Yonsei University for reviewing and recommending this manuscript.

\section{Conflict of Interest}

This paper was supported by National Research Foundation (NRF) of Korea in 2009 (NRF-2009-351-E00036).

\section{References}

[1] Marrs, J.A. and Lowry, L.W. (2006) Nursing Theory and Practice: Connecting the Dots. Nursing Science Quarterly, 19, 44-50. https://doi.org/10.1177/0894318405283547

[2] Parse. R.R. (1987) Nursing Science: Major Paradigms, Theories, and Critiques. Saunders, Philadelphia.

[3] Newman, M.A., Sime, A.M. and Corcoran-Perry, S.A. (1991) The Focus of the Discipline of Nursing. Advances in Nursing Science, 14, 1-6. https://doi.org/10.1097/00012272-199109000-00002

[4] Roy, C. and Jones, D.A. (2007) Nursing Knowledge Development and Clinical Practice. Springer Publishing Company, LLC, New York.

[5] Carper, B.A. (1978) Fundamental Patterns of Knowing in Nursing. Advances in Nursing Science, 1, 13-23. https://doi.org/10.1097/00012272-197810000-00004

[6] White, J. (1995) Patterns of Knowing: Review, Critique, and Update. Advances in Nursing Science, 17, 73-86. https://doi.org/10.1097/00012272-199506000-00007

[7] Chinn, P.L. and Kramer, M.K. (2004) Integrated Knowledge Development in Nursing. Mosby, St. Louis.

[8] Jones, D.A. (2007) A Synthesis of Philosophical Perspectives for Knowledge Development. In: Roy, C. and Jones, D.A., Eds., Nursing Knowledge Development and Clinical Practice, Springer Publishing Company, New York, 163-176.

[9] Roy, C. (2007) Advances in Nursing Knowledge and the Challenge for Transforming Practice. In: Roy, C. and Jones, D.A., Eds., Nursing Knowledge Development and Clinical Practice, Springer Publishing Company, New York, 3-37. 
[10] Parse, R.R. (1998) The Human Becoming School of Thought: A Perspective for Nurses and Other Health Professionals. Sage, Thousand Oaks, CA.

[11] Newman, M.A. (1999) Health as Expanding Consciousness. Jones \& Bartlett Learning, New York.

[12] Goodwin, Z, Kiehl, E.M. and Peterson, J.Z. (2002) King's Theory as Foundation for an Advance Directive Decision-Making Model. Nursing Science Quarterly, 15, 237-241. https://doi.org/10.1177/08918402015003010

[13] Ruland, C.M. and Moore, S.M. (1998) Theory Construction Based on Standards of Care: A Proposed Theory of the Peaceful End of Life. Nursing Outlook, 46, 169-175. https://doi.org/10.1016/S0029-6554(98)90069-0

[14] Breakey, S. (2006) Optimizing Stewardship: A Grounded Theory of Nurses as Moral Leaders in the Intensive Care Unit. Unpublished Doctoral Dissertation, Boston College, MA.

[15] Barron, A. (2005) Suffering, Growth, and Possibility: Health as Expanding Consciousness in End-of-Life Care. In: Picard, C. and Jones, D., Eds., Giving Voice to What We Know. Margaret Newman's Theory of Health as Expanding Consciousness in Nursing Practice, Research, and Education, Jones and Bartlett, Sudbury, 43-52.

[16] Zust, B.L. (2006) Death as a Transformation of Wholeness: An "Aha” Experience of Health as Expanding Consciousness. Nursing Science Quarterly, 19, 57-60. https://doi.org/10.1177/0894318405283555

[17] The SUPPORT Principal Investigators (1995) A Controlled Trial to Improve Care for Seriously Ill Hospitalized Patients. The Study to Understand Prognoses and Preferences for Outcomes and Risks of Treatments (SUPPORT). JAMA, 274, 1591-1598. https://doi.org/10.1001/jama.1995.03530200027032

[18] Ferrell, B.R. (2006) Understanding the Moral Distress of Nurses Witnessing Medically Futile Care. Oncology Nursing Forum, 33, 922-930. https://doi.org/10.1188/06.ONF.922-930

[19] Ferrell, B.R., Grant, M. and Virani, R. (1999) Strengthening Nursing Education to Improve End-of-life Care. Nursing Outlook, 47, 252-256. https://doi.org/10.1016/S0029-6554(99)90022-2

[20] Ferrell, B.R. Virani, R., Grant, M., Rhome, A., Malloy, P., Bednash, G. and Grimm, M. (2005) Evaluation of the End-of-Life Nursing Education Consortium Undergraduate Faculty Training Program, Journal of Palliative Medicine, 8, 107-114. https://doi.org/10.1089/jpm.2005.8.107

[21] Ferrell, B.R., Virani, R. and Malloy, P. (2006) Evaluation of the End-of-Life Nursing Education Consortium Project in the USA. International Journal of Palliative Nursing, 12, 269-276. https://doi.org/10.12968/ijpn.2006.12.6.21452

[22] Brooten, D. and Youngblut, J.M. (2006) Nurse Dose as a Concept. Journal of Nursing Scholarship, 38, 94-99. https://doi.org/10.1111/j.1547-5069.2006.00083.x

[23] Lee, W., Kim, C.J., Roh, Y.S., Shin, H. and Kim, M.J. (2007) Clinical Track Faculty: Merits and Issues. Journal of Professional Nursing, 23, 5-12. https://doi.org/10.1016/j.profnurs.2006.12.003

[24] Bunkers, S.S. (2002) Nursing Science as Human Science: The New World and Human Becoming. Nursing Science Quarterly, 15, 25-30. https://doi.org/10.1177/08943180222108732

[25] Lindsay, G.M. and Smith, F. (2003) Narrative Inquiry in a Nursing Practicum. Nursing Inquiry, 10, 121-129. https://doi.org/10.1046/j.1440-1800.2003.00165.x 
[26] Lee, S.M. (2005) Doctoral Student Exemplar: Transformation of the Patient-Nurse Dyad. In: Picard, C. and Jones, D., Eds., Giving Voice to What We Know: Margaret Newman's Theory of Health as Expanding Consciousness in Nursing Practice, Research, and Education, Jones and Bartlett, Sudbury, 187-202.

[27] Cangelosi, P. and Whitt, K. (2006) Teaching through Storytelling: An Exemplar. International Journal of Nursing Education Scholarship, 3, Article 2. https://doi.org/10.2202/1548-923X.1175

[28] Forneris, S.G. and Peden-McAlpine, C.J. (2006) Contextual Learning: A Reflective Learning Intervention for Nursing Education. International Journal of Nursing Education Scholarship, 3, Article 17. https://doi.org/10.2202/1548-923X.1254 